\title{
FUNCTIONS WHOSE DERIVATIVE HAS A POSITIVE REAL PART ${ }^{(1)}$
}

BY

\author{
T. H. MACGREGOR
}

1. Introduction. Let $R$ denote the class of functions which are regular and satisfy $\operatorname{Re} f^{\prime}(z)>0$ for $|z|<1$ and are normalized by $f(0)=0$ and $f^{\prime}(0)=1$. This paper develops some properties of functions in $R$.

An early consideration of functions satisfying the condition $\operatorname{Re} f^{\prime}(z)>0$ can be found in a paper by J. W. Alexander [1, p. 18]. He proves: if $f(z)$ is regular in $|z|<1$ and $f^{\prime}(z)$ "maps $|z|<1$ upon a region contained within a half-plane bounded by a straight line through the origin" then $f(z)$ is schlicht for $|z|<1$.

J. Wolff [11] showed that $f(z)$ is schlicht in $\operatorname{Re} z>0$ if it is regular there and satisfies $\operatorname{Re} f^{\prime}(z)>0$. K. Noshiro [6, p. 151] and S. Warschawski [10, p. 312] each demonstrated that $\operatorname{Re} f^{\prime}(z)>0$ is a sufficient condition for the schlichtness of $f(z)$ in any convex domain.

Conversely, S. R. Tims [9] proved that for each simply connected nonconvex domain $D$ there is a function $f(z)$ regular in $D$ such that $\operatorname{Re} f^{\prime}(z)>0$ and $f(z)$ is not schlicht in $D$. This result is a particular consequence of some more general theorems contained in a paper by F. Herzog and G. Piranian [2]. They determine both necessary and sufficient conditions for a domain $D$-not necessarily simply connected - to have the property that every function regular and satisfying $\operatorname{Re} f^{\prime}(z)>0$ in $D$ is schlicht there.

A more general class of functions than those satisfying $\operatorname{Re} f^{\prime}(z)>0$ is the class of close-to-convex functions. W. Kaplan [3] calls a function $f(z)$ close-to-convex in $|z|<1$ providing there is a function $g(z)$ analytic, schlicht and convex in $|z|<1$ for which $\operatorname{Re}\left\{f^{\prime}(z) / g^{\prime}(z)\right\}>0$. Each function close-toconvex in $|z|<1$ is schlicht there.

Because of Alexander's result each function in $R$ is schlicht in $|z|<1$. Functions in $R$ can be constructed by integrating functions $g(z)=1+b_{1} z+\cdots$ which satisfy $\operatorname{Re} g(z)>0$ for $|z|<1$. The function $f(z)=-z-2 \log (1-z)$ is in $R$ for its derivative if $f^{\prime}(z)=(1+z) /(1-z)$ and $w=(1+z) /(1-z)$ maps $|z|<1$ onto $\operatorname{Re} w>0$.

2. Distortion theorems. The following lemma contains results due to C. Caratheodory. A proof can be found in [7, Vol. 1, Problem 235, p. 129, and Vol. 1, Problem 287, p. 140].

Lemma. If $g(z)=1+\sum_{n=1}^{\infty} b_{n} z^{n}$ is regular in $|z|<1$ and $\operatorname{Re} g(z)>0$ then

Received by the editors June 16, 1961 and, in revised form, September 26, 1961.

(1) This paper is part of the author's dissertation done at the University of Pennsylvania. 
$\left|b_{n}\right| \leqq 2$ for $n \geqq 1,|g(z)| \leqq(1+|z|) /(1-|z|)$, and $\operatorname{Re} g(z) \geqq(1-|z|) /(1+|z|)$.

This lemma has similar forms without the normalization $g(0)=1$. For example, $\left|b_{n}\right| \leqq 2\left|b_{0}\right|$ if $b_{0}=g(0)$.

THEOREM 1. If $f(z)=z+\sum_{n=2}^{\infty} a_{n} z^{n} \in R$ then

$$
\begin{aligned}
\left|a_{n}\right| & \leqq \frac{2}{n} \quad \text { for } n=2,3, \cdots, \\
\left|f^{\prime}(z)\right| & \leqq \frac{1+|z|}{1-|z|}, \\
\operatorname{Re} f^{\prime}(z) & \geqq \frac{1-|z|}{1+|z|}, \\
|f(z)| & \leqq-|z|-2 \log (1-|z|), \\
|f(z)| & \geqq-|z|+2 \log (1+|z|) .
\end{aligned}
$$

Proof. Since $\operatorname{Re} f^{\prime}(\xi)>0$ the estimates (1), (2), and (3) are immediate consequences of the lemma where $g(z)=f^{\prime}(z)$.

Using (2) and (3) we can arrive at (4) and (5) by integration, as follows.

$$
\begin{aligned}
f(z) & =\int_{0}^{z} f^{\prime}(\sigma) d \sigma \int_{0}^{|z|} f^{\prime}\left(t e^{i \phi}\right) e^{i \phi} d t, \\
|f(z)| & \leqq \int_{0}^{|z|}\left|f^{\prime}\left(t e^{i \phi}\right)\right| d t \leqq \int_{0}^{|z|} \frac{1+t}{1-t} d t=-|z|-2 \log (1-|z|), \\
|f(z)| & \geqq \int_{0}^{|z|} \operatorname{Re} f^{\prime}\left(t e^{i \phi}\right) d t \geqq \int_{0}^{|z|} \frac{1-t}{1+t} d t=-|z|+2 \log (1+|z|) .
\end{aligned}
$$

This proves the theorem. By considering the function $f(z)=-z-2 \log (1-z)$ $=z+\sum_{n=2}^{\infty}(2 / n) z^{n}$ one can show that all estimates of this theorem are sharp. The next result follows from estimate (5).

COROLlary. Each function in $R$ maps $|z|<1$ onto a domain which covers the disc $|w|<2 \log 2-1$.

\section{The radius of convexity.}

TheOREM 2. Each function in $R$ maps $|z|<2^{1 / 2}-1$ onto a convex domain.

Proof. Suppose that $g(z)$ is regular for $|z|<1$ and $\operatorname{Re} g(z)>0$. Let $\sigma$ be any complex number such that $|\sigma|<1$. The function $G(z)=g((z+\sigma) /(1+\bar{\sigma} z))$ $=g(\sigma)+g^{\prime}(\sigma)\left(1|\sigma|^{2}\right) z+\ldots$ is regular for $|z|<1$ and $\operatorname{Re} G(z)>0$. Accordingly, if $G(z)=b_{0}+b_{1} z+\cdots$ then $\left|b_{1}\right| \leqq 2\left|b_{0}\right|$. This gives $\left|g^{\prime}(\sigma) / g(\sigma)\right|$ $\leqq 2 /\left(1-|\sigma|^{2}\right)$.

Applying this inequality to $g(z)=f^{\prime}(z)$ where $f(z) \in R$ gives $\left|f^{\prime \prime}(z) / f^{\prime}(z)\right|$ 
$\leqq 2 /\left(1-|z|^{2}\right)$. Then, $\operatorname{Re}\left\{z f^{\prime \prime}(z) / f^{\prime}(z)\right\} \geqq-2|z| /\left(1-|z|^{2}\right)$.

Now, $f(z)$ maps $|z|<r$ onto a convex domain is equivalent to the condition $\operatorname{Re}\left\{\left[z f^{\prime \prime}(z) / f^{\prime}(z)\right]+1\right\}>0$ for $|z|<r$ [7, Vol. 1, Problem 108, p. 105]. Hence, the image domain is convex for $f(z) \in R$ if $-2|z| /\left(1-|z|^{2}\right)+1>0$, i.e., if $|z|<2^{1 / 2}-1$.

For the function $f(z)=-z-2 \log (1-z)$ we have $\left[z f^{\prime \prime}(z) / f^{\prime}(z)\right]+1$ $=\left(1+2 z-z^{2}\right) /\left(1-z^{2}\right)$ and this last expression vanishes for $z=1-2^{1 / 2}$. Hence, this function maps no circle $|z|<r$ larger than $|z|<2^{1 / 2}-1$ onto a convex domain.

THEOREM 3. If $f(z)=z+a_{2} z^{2}+\cdots$ is regular in $|z|<1$ and $\operatorname{Re}\{f(z) / z\}$ $>0$ then $f(z)$ is schlicht in $|z|<2^{1 / 2}-1$.

Proof. Let $g(z)=f(z) / z$. Then since $\operatorname{Re} g(z)>0$ the estimate deduced early in the proof of Theorem 2 gives $\left|g^{\prime}(z) / g(z)\right| \leqq 2 /\left(1-|z|^{2}\right)$. We have the relation $z f^{\prime}(z) / f(z)=1+\left[z g^{\prime}(z) / g(z)\right]$. Thus,

$$
\operatorname{Re}\left\{\frac{z f^{\prime}(z)}{f(z)}\right\} \geqq 1-\left|\frac{z g^{\prime}(z)}{g(z)}\right| \geqq 1-\frac{2|z|}{1-|z|^{2}}=\frac{1-2|z|-|z|^{2}}{1-|z|^{2}} .
$$

The last expression is positive if $|z|<2^{1 / 2}-1$. Thus, for $|z|<2^{1 / 2}-1$ we have $\operatorname{Re}\left\{z f^{\prime}(z) / f(z)\right\}>0$. However, the condition $\operatorname{Re}\left\{z f^{\prime}(z) / f(z)\right\}>0$ is sufficient for the schlichtness of $f(z)$ in $|z|<r$ [7, Vol. 1, Problem 109, p. 105].

The function $f(z)=\left(z+z^{2}\right) /(1-z)$ satisfies $\operatorname{Re}\{f(z) / z\}>0$ for $|z|<1$ and its derivative vanishes at $z=1-2^{1 / 2}$. Thus, this function is not schlicht in any circle $|z|<r$ larger than $|z|<2^{1 / 2}-1$.

4. Schlichtness of the partial sums. It is of interest to determine to what extent a given property of a power series is carried over to its partial sums. G. Szegö [8] has shown that all of the partial sums of a function schlicht in $|z|<1$ are schlicht in $|z|<1 / 4$. For the functions in $R$ we can improve $1 / 4$ to $1 / 2$.

THEOREM 4. If $f(z)=z+\sum_{n=2}^{\infty} a_{n} z^{n} \in R$ and $f_{n}(z)=z+a_{2} z^{2}+\cdots+a_{n} z^{n}$ then $f_{n}(z)$ is schlicht in $|z|<1 / 2$ for $n=2,3, \cdots$.

Proof. Suppose that $g(z)=1+\sum_{n=1}^{\infty} b_{n} z^{n}$ is regular for $|z|<1$ and $\operatorname{Re} g(z)$ $>0$. Let $s_{n}(z)=1+b_{1} z+\cdots+b_{n} z^{n}$. We will prove that $\operatorname{Re} s_{n}(z)>0$ for $|z|<1 / 2$. From this the theorem follows. For, if we let $g(z)=f^{\prime}(z)$ then $s_{n}(z)=f_{n}^{\prime}(z)$ and then $\operatorname{Re} f_{n}^{\prime}(z)>0$ for $|z|<1 / 2$. However, this is a sufficient condition for the schlichtness of $f_{n}(z)$ in $|z|<1 / 2$.

Let $r_{n}(z)=g(z)-s_{n}(z)$.

$$
\left|r_{n}(z)\right|=\left|\sum_{k=n+1}^{\infty} b_{k} z^{k}\right| \leqq \sum_{k=n+1}^{\infty}\left|b_{k} z^{k}\right| \leqq \sum_{k=n+1}^{\infty} 2|z|^{k}=\frac{2|z|^{n+1}}{1-|z|} .
$$

Since $\operatorname{Re} g(z)>0$ we have $\operatorname{Re} g(z) \geqq(1-|z|) /(1+|z|)$. 


$$
\operatorname{Re} s_{n}(z) \geqq \operatorname{Re} g(z)-\left|r_{n}(z)\right| \geqq \frac{1-|z|}{1+|z|}-\frac{2|z|^{n+1}}{1-|z|}
$$

If $|z|=1 / 2$ and $n \geqq 3$ this last estimate yields $\operatorname{Re} s_{n}(z) \geqq 1 / 3-1 / 4>0$. Since $\operatorname{Re} s_{n}(z)$ is harmonic it assumes its minimum for $|z| \leqq r$ on $|z|=r$. Therefore, we have shown that $\operatorname{Re} s_{n}(z)>0$ in $|z|<1 / 2$ for $n \geqq 3$.

For the case $n=1$ we have $\operatorname{Re} s_{1}(z) \geqq 1-\left|b_{1} z\right| \geqq 1-2|z|$. Thus, $\operatorname{Re} s_{1}(z)>0$ in $|z|<1 / 2$.

Finally, we consider $n=2$. First we find a relation between $b_{1}$ and $b_{2}$. The function $G(z)=(g(z)-1) /(g(z)+1)$ is regular in $|z|<1, G(0)=0$, and $|G(z)|<1$. Thus, the function $H(z)=G(z) / z$ is regular in $|z|<1$ and $|H(z)|$ $\leqq 1$. For such functions $H(z)=c_{0}+c_{1} z+\cdots$ we have $\left|c_{1}\right| \leqq 1-\left|c_{0}\right|^{2}[5$, p. 172, Problem 9]. Here, $H(z)=\left(b_{1} / 2\right)+\left(\left(2 b_{2}-b_{1}^{2}\right) / 4\right) z+\cdots$ This gives the result $\left|2 b_{2}-b_{1}^{2}\right| \leqq 4-\left|b_{1}\right|^{2}$.

Let $c=2 b_{2}-b_{1}^{2},|z| \leqq 1 / 2, b_{1} z=\alpha+i \beta, c^{1 / 2} z=\gamma+i \delta$. Then, $s_{2}(z)=1+b_{1} z$ $+(c / 2) z^{2}+\left(b_{1}^{2} / 2\right) z^{2}$.

$$
\begin{aligned}
\operatorname{Re} s_{2}(z) & =1+\alpha+\left(\gamma^{2} / 2\right)-\left(\delta^{2} / 2\right)+\left(\alpha^{2} / 2\right)-\left(\beta^{2} / 2\right) \\
& =1+\alpha+\left(\alpha^{2} / 2\right)-\left(\beta^{2} / 2\right)+\left(\gamma^{2} / 2\right)-(1 / 2)\left(\left|c z^{2}\right|-\gamma^{2}\right) \\
& \geqq 1+\alpha+\left(\alpha^{2} / 2\right)-\left(\beta^{2} / 2\right)+\left(\gamma^{2} / 2\right)-(1 / 2)\left(1-(1 / 4)\left|b_{1}^{2}\right|-\gamma^{2}\right) \\
& \geqq 1+\alpha+\left(\alpha^{2} / 2\right)-\left(\beta^{2} / 2\right)+\left(\gamma^{2} / 2\right)-(1 / 2)\left(1-\alpha^{2}-\beta^{2}-\gamma^{2}\right) \\
& =(1 / 2)+\alpha+\alpha^{2}+\gamma^{2} \\
& \geqq(1 / 2)+\alpha+\alpha^{2} \geqq 1 / 4>0 .
\end{aligned}
$$

5. Further extremal properties of $f(z)=-z-2 \log (1-z)$.

TheOREM 5. Suppose $0<r<1$. The area of the image of $|z|<r$ for functions in $R$ is maximal for $f(z)=-z-2 \log (1-z)$. This function also maximizes the length of the image of $|z|=r$ for the class $R$.

Proof. Suppose that $f(z)=z+\sum_{n=2}^{\infty} a_{n} z^{n} \in R$. Let $A_{r}(f)$ denote the area of the image of $|z|<r$ under $f(z)$.

$$
\begin{aligned}
A_{r}(f) & =\int_{|z|} \int_{<r}\left|f^{\prime}(z)\right|^{2} d x d y \\
& =\int_{0}^{r} \int_{0}^{2 \pi}\left|f^{\prime}\left(t e^{i \phi}\right)\right|^{2} d \phi t d t \\
& =\pi\left\{r^{2}+\sum_{n=2}^{\infty} n\left|a_{n}\right|^{2} r^{2 n}\right\} \\
& \leqq \pi\left\{r^{2}+\sum_{n=2}^{\infty} n(2 / n)^{2} r^{2 n}\right\} \\
& =A_{r}\left(f_{0}\right) \text { where } f_{0}(z)=-z-2 \log (1-z) .
\end{aligned}
$$


There is another proof of this part of the theorem and the idea involved gives a short proof of the rest of the theorem. This is concerned with the principle of subordination.

Suppose that $G(z)$ is regular and schlicht in $|z|<1$ and maps $|z|<1$ onto the domain $G$. Let $g(z)$ be regular in $|z|<1$ and assume values all of which lie in $G$. Also, suppose that $g(0)=G(0) . g(z)$ is called subordinate to $G(z)$ in $|z|<1$.

If $f(z) \in R$ then $f^{\prime}(z)$ is subordinate to $w=(1+z) /(1-z)$. This function is the derivative of $f_{0}(z)=-z-2 \log (1-z)$.

J. E. Littlewood [4, p. 484, Theorem 2] has shown that if $g(z)$ is subordinate to $G(z)$ in $|z|<1$ then for any $k>0$

$$
\int_{0}^{2 \pi}\left|g\left(r e^{i \phi}\right)\right|^{k} d \phi \leqq \int_{0}^{2 \pi}\left|G\left(r e^{i \phi}\right)\right|^{k} d \phi .
$$

Applying this inequality for $k=2$ to the derivative of functions in $R$ leads to a second proof of the first half of the theorem. Similarly applying this estimate for $k=1$ proves the second part of the theorem, as follows. Suppose that $f(z) \in R$. Let $L_{r}(f)$ denote the length of the image of $|z|=r$ under $f(z)$.

$$
L_{r}(f)=\int_{0}^{2 \pi}\left|f^{\prime}\left(r e^{i \phi}\right)\right| r d \phi \leqq \int_{0}^{2 \pi}\left|f_{0}\left(r e^{i \phi}\right)\right| r d \phi=L_{r}\left(f_{0}\right) .
$$

\section{Functions with initial zero coefficients.}

THEOREM 6. If $f(z)=z+a_{k} z^{k}+a_{k+1} z^{k+1}+\cdots \in R$ then

$$
\begin{aligned}
& \left|f^{\prime}(z)\right| \leqq \frac{1+|z|^{k-1}}{1-|z|^{k-1}}, \\
& \operatorname{Re} f^{\prime}(x) \geqq \frac{1-|z|^{k-1}}{1+|z|^{k-1}}, \\
& |f(z)| \leqq \int_{0}^{|z|} \frac{1+t^{k-1}}{1-t^{k-1}} d t, \\
& |f(z)| \geqq \int_{0}^{|z|} \frac{1-t^{k-1}}{1+t^{k-1}} d t .
\end{aligned}
$$

Proof. Suppose that $g(z)=1+b_{k} z^{k}+\cdots$ is regular and satisfies $\operatorname{Re} g(z)$ $>0$ for $|z|<1$. Then $G(z)=(1-g(z)) /(1+g(z))$ is regular for $|z|<1$ and $|G(z)|<1$. Also, $G(z)$ has a zero at $z=0$ of order at least $k$. Thus, according to the form of Schwarz's lemma for this situation we have $|G(z)| \leqq|z|^{k}$. By considering $g(z)$ as a function of $G(z)$ this inequality implies that $g(z)$ assumes values which lie in the closed disc with center at $\left(1+|z|^{2 k}\right) /\left(1-|z|^{2 k}\right)$ and with radius $2|z|^{2 k} /\left(1-|z|^{2 k}\right)$. From this we can infer the estimates $|g(z)|$ 
$\leqq\left(1+|z|^{k}\right) /\left(1-|z|^{k}\right), \operatorname{Re} g(z) \geqq\left(1-|z|^{k}\right) /\left(1+|z|^{k}\right)$. Applying these results to $f^{\prime}(z)$ gives (1) and (2).

The inequalities (3) and (4) follow from (1) and (2), respectively, by integration. This is similar to the proof of Theorem 1.

If, in particular, we apply Theorem 6 to functions in $R$ for which $a_{2}=0$ we obtain from (3) and (4) the following: $-|z|+(2 /|z|) \operatorname{Arctan}|z| \leqq|f(z)|$ $\leqq-|z|+\log ((1+|z|) /(1-|z|))$. From the lower bound we can infer the next result.

Corollary. If $f(z) \in R$ and $f^{\prime \prime}(0)=0$ then the image domain covers the disc $|w|<(\pi / 2)-1$.

If $f(z)=z+a_{k} z^{k}+\cdots \in R$ then $f^{\prime}(z)$ is subordinate to $w=\left(1+z^{k-1}\right) /\left(1-z^{k-1}\right)$. By means of Littlewood's inequalities we can argue similarly as in Theorem 5 to deduce the next theorem.

Theorem 7. Suppose that $0<r<1, f_{k}(z)=\int_{0}^{3}\left(1+\sigma^{k-1}\right) /\left(1-\sigma^{k-1}\right) d \sigma$. The area of the image of $|z|<r$ for functions $f(z)=z+a_{k} z^{k}+\cdots$ in $R$ is maximal for $f_{k}(z)$. Also, $f_{k}(z)$ maximizes the length of the image of $|z|=r$ for all such functions.

\section{REFERENCES}

1. J. W. Alexander, Functions which map the interior of the unit circle upon simple regions, Ann. of Math. 17 (1915), 12-22.

2. F. Herzog and G. Piranian, On the univalence of functions whose derivative has a positive real part, Proc. Amer. Math. Soc. 2 (1951), 625-633.

3. W. Kaplan, Close-to-convex schlicht functions, Michigan Math. J. 1 (1952), 169-185.

4. J. E. Littlewood, On inequalities in the theory of functions, Proc. London Math. Soc. (2) 23 (1925), 481-519.

5. Z. Nehari, Conformal mapping, McGraw-Hill, New York, 1952.

6. K. Noshiro, On the theory of schlicht functions, J. Fac. Sci. Hokkaido Univ. (1) 2 (19341935), 129-155.

7. G. Polya und G. Szegö, Aufgaben und Lehrsätze aus der Analysis, Springer, Berlin, 1954.

8. G. Szegö, Zur Theorie der schlichten Abbildungen, Math. Ann. 100 (1928), 188-211.

9. S. R. Tims, $A$ theorem on functions schlicht in convex domains, Proc. London Math. Soc. (3) 1 (1951), 200-205.

10. S. Warschawski, On the higher derivatives at the boundary in conformal mappings, Trans. Amer. Math. Soc. 38 (1935), 310-340.

11. J. Wolff, L'integrale d'une function holomorphe et d partie reelle positive dans un demiplan est univalente, C. R. Acad. Sci. Paris 198 (1934), 1209-1210.

Lafayette College,

Easton, Pennsyluania 